\title{
ZINC AND OTHER ACTIVE SITE METALS AS PROBES OF LOCAL CONFORMATION AND FUNCTION OF ENZYMES
}

\author{
by \\ BERT L. VALLEE

\begin{abstract}
Biophysics Research Laboratory, Department of Biochemistry, Harvard Medical School, and Brigham and Women's Hospital Boston, MA 02115

Presented as the 6th Linderstrem-Lang Lecture

at the Carlsberg Laboratory, Copenhagen, on 28 November 1980
\end{abstract}

Keywords: Metalloenzymes, protein-conformations, entatic state, carboxypeptidase A, cobalt carboxypeptidase, resonance Raman spectroscopy

\section{ZINC METALLOENZYMES}

Knowledge regarding the biological occurrence and function of zinc, the development of methods that permit its detection, and those aspects of biochemistry that have allowed an appreciation of the manner in which it participates in generating biological specificity have grown exponentially in the last decade. The chemical basis of enzyme specificity, the properties of metalloenzymes that have served to channel this information and the interaction of the metal in cellular growth and development, as that relates to the development of the whole organism, are of particular interest.
Zinc metalloenzymes have emerged on the scene only relatively recently as a broad general class. The discovery in 1940 by KEILIN and MANN (29) that carbonic anhydrase contains zinc that is essential to its mechanism of action was the first concrete demonstration of a specific biological function for this element. Over the next twenty years, only five additional zinc metalloenzymes were identified, but by now more than 120 are on record (Table I).

Zinc metalloenzymes exhibit perhaps the greatest diversity both of catalytic function and of roles played by the metal atom $(44,64,65)$. They are now known to be present throughout

\footnotetext{
* The original work reported here was supported by Grant-in-Aid GM-15003 from the National Institutes of Health of the Department of Health, Education and Welfare.
} 
Table I

Zinc metalloenzymes, 1980.

\begin{tabular}{|c|c|c|}
\hline Enzyme & No. ${ }^{a}$ & Source \\
\hline Alcohol dehydrogenase & 5 & yeast, plants, vertebrates \\
\hline D-Lactate cytochrome reductase & 1 & yeast \\
\hline Superoxide dismutase & 6 & plants, vertebrates \\
\hline Aspartate transcarbamylase & 1 & E. coli \\
\hline Transcarboxylase & 1 & P. shermanii \\
\hline Phosphoglucomutase & 1 & yeast \\
\hline RNA polymerase I and II & 2 & E. gracilis \\
\hline RNA polymerase I and II & 2 & yeast \\
\hline RNA polymerase II & 1 & wheat germ \\
\hline DNA polymerase I and II & 2 & E. coli, sea urchin \\
\hline Reverse transcriptase & 5 & oncogenic viruses \\
\hline Mercaptopyruvate sulfur transferase & 1 & E. coli \\
\hline Alkaline phosphatase & 5 & E. coli, vertebrates (intestine, placenta) \\
\hline Phospholipase C & 1 & B. cereus \\
\hline Leucine aminopeptidase & 4 & kidney, lens, yeast \\
\hline Particulate leucine aminopeptidase & 1 & kidney \\
\hline Carboxypeptidase A & 4 & pancreas \\
\hline Carboxypeptidase B & 2 & pancreas \\
\hline Collagenase & 1 & Clostridium histolyticum \\
\hline Procarboxypeptidase A & 2 & pancreas \\
\hline Procarboxypeptidase B & 1 & pancreas \\
\hline Carboxypeptidase $\mathrm{G} 1$ & 1 & P. stutzeri \\
\hline Dipeptidase & 2 & kidney, mouse tumor \\
\hline Neutral protease & 7 & bacteria \\
\hline AMP aminohydrolase & 1 & muscle \\
\hline Aldolase & 3 & yeast, A. niger, B. stearothermophilus \\
\hline L-Rhamnulose 1-phosphate aldolase & 1 & E. coli \\
\hline Carbonic anhydrase & 18 & vertebrates, erythrocytes, muscles, plants \\
\hline$\delta$-A minolevulinic acid dehydratase & 1 & liver \\
\hline Phosphomannose isomerase & 1 & yeast \\
\hline Pyruvate carboxylase & 1 & yeast \\
\hline Protein elongation factor & 1 & liver \\
\hline$\alpha$-D-Mannosidase & $i$ & jack bean \\
\hline$\beta$-Lactamase II & 1 & B. cereus \\
\hline tRNA synthetase & 2 & E. coli \\
\hline Deoxynucleotidyl transferase & 1 & calf thymus \\
\hline
\end{tabular}

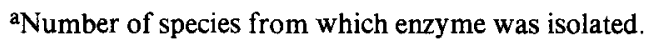

all phyla and participate in a wide variety of metabolic processes, including carbohydrate, lipid, protein, and nucleic acid synthesis or degradation. Each of the six categories of enzymes designated by the IUB Commission on Enzyme Nomenclature contains at least one example of a zinc metalloenzyme.

\section{The entatic state}

The complex ions of zinc generally have a tetrahedral configuration, but the element can accommodate up to six ligands, and octahedral complexes are also well known. It is quite likely that the coordination characteristics of zinc in metalloenzymes differ from those found in, for example, simple halo-, cyano-, and aminocomplexes. Because of the completed d subshell, there is no ligand field stabilization in zinc complexes. Hence, their stereochemistry is determined largely by ligand size and electrostatic and covalent binding forces. Constraints induced by the three-dimensional structure of the protein, ligand heterogeneity, and the possibility of 
varying degrees of hydrophobicity in the immediate environment of the metal binding site can all combine to generate atypical coordination properties. Unusual bond lengths, distorted geometries, and/or an odd number of ligands can join to result in a site on the enzyme which is thermodynamically more energetic than if the metal were free in solution and complexed to simpler ligands. The purpose of this apparently abnormal situation would be to poise the metal for its intended biologic function, i.e., assisting in the catalysis of a metabolic reaction. This description of the state of a zinc ion in a zinc metalloenzyme has been defined by VALLEE and Williams (68) as the entatic state. The term entasis is used in this context to indicate a condition of tension or stress in the metalloenzymes which exists prior to interaction with substrate.

The entatic state effectively originates in the genetic heritage of the cell. The primary structure of the enzyme protein dictates the relative spatial position of those amino acid side chains destined to serve as ligands when the apoprotein combines with the metal ion. Evidence suggests that the metal ion is not incorporated into the growing, ribosome-bound polypeptide chain, but only into the fully formed protein (18). Hence, the metal does not induce its own coordination site but must await the expression of the genetic message.

\section{Chemistry of zinc: Its recognition and roles in enzymes}

Since the $\mathrm{Zn}^{2}+$ ion has a completed $\mathrm{d}$ subshell of electrons, it is diamagnetic, inveristics of transition elements such as iron, copper, manganese, or cobalt. The late recognition of zinc, relative to these other metals, as an important cell nutrient in part derives from this absence of probe properties and consequent lack of easy detectability. The development of very sensitive and precise commercial instrumentation for zinc analysis was a most important factor in bringing zinc to its current position of prominence in metallobiochemistry. Fifteen years ago a talented investigator could analyze, at most, only 10 samples per day by using the colorimetric dithizone method, which required milligram quantities of protein containing microgram quantities of zinc. Now, by using atomic absorption spectrometry, samples can be analyzed automatically in less than a minute with two to three orders of magnitude better sensitivity. More recently developed methods such as microwave excitation emission and atomic fluorescence promise to enhance further the present analytical capabilities. The quantitation of zinc in biologic samples no longer constitutes a ratelimiting step to progress.

Chemical stability may well be an essential aspect of the utilization of zinc in diverse biological processes such as hydrolysis, transfer, addition to double bonds, and even oxidoreduction. Thus, the role of zinc in redox enzymes such as alcohol dehydrogenase is not to donate or accept electrons; rather, it serves as a Lewis acid. It is this capacity of serving as a super acid which likely underlies the function of zinc in many zinc metalloenzymes. A zinc metalloenzyme is defined as a catalytically active metallo. protein containing stoichiometric amounts of zinc firmly bound at its active site (63). The metal atoms are bound so tightly that they do not dissociate from the protein during the isolation procedure. When the metal is bound loosely the association is chemically and functionally more tenuous, and the designation metal-enzyme com plex has been employed to convey this distinction.

In zinc metalloenzymes, the metal is located at the active site and participates in the actual catalytic process. However, this is not the only function zinc may have in enzymes. It may serve to stabilize structure, as in Bacillus subtilis $\alpha$-amylase (69), or it may have a solely structural role, as in aspartate transcarbamylase (54). It can serve in both catalysis and structure, e.g., horse liver alcohol dehydrogenase (15) and alkaline phosphatase of E. coli, or in both catalysis and regulation, e.g., bovine lens aminopeptidase (13).

In the past few years, zinc has been found to be essential to the functions of both DNA and RNA polymerases, providing a partial clue as to the basis of the profound effects of zinc deficiency on the growth of all organisms. The RNA-dependent DNA polymerases (reverse transcriptases) of avian myeloblastosis and other viruses, are also zinc metalloenzymes (5). Early findings had suggested an interaction between zinc metabolism and leukemia (64), and the 
involvement of zinc in the synthesis of nucleic acids now provides concrete avenues for the exploration of this relationship.

\section{Metals of metalloenzymes as probes in the study of enzyme conformation and function}

The integrity of the three-dimensional structure and a suitable conformation of a given enzyme molecule are thought to be critical to its catalytic potential. While numerous experimental approaches have been designed for elucidating such structure-function relationships, only a limited number have been found useful for examining the subtle conformational changes that occur in the course of the actual catalytic process itself. Those which are effective identify both substrate-binding and catalytic groups and serve as appropriate probes of the catalytic reaction. If such groups can signal changes in their mutual interactions at rates at least as fast as catalysis, each of the accompanying dynamic events can be observed directly. Such information is essential to comprehend and verify enzyme mechanisms.

$\mathrm{X}$-ray structural analysis of enzyme-substrate and/or enzyme-inhibitor complexes has greatly aided current understanding of the mode of interaction of substrate analogues with the active sites of enzymes. While such studies have served as the basis for deductions regarding the dynamics of enzyme action, the time-averaging nature of the approach precludes the direct observation of transient intermediates. The hypothesis that the structure of an enzyme in the crystalline state is the same as that in solution is implicit in such deductions. However, there is much evidence that enzymes in solution have multiple, rapidly-interconverting conformations $(10,19,73)$ as predicted by LiNDERSTRgM-LANG and Schellman (37). Crystallization introduces interactions, e.g., crystal packing forces, with energetics comparable to those necessary for maintaining particular conformations themselves. Thus, the three-dimensional structures of enzymes in crystals and solutions need not always be identical. Different crystal forms could well comprise multiple and/or different populations of enzyme conformers. This has been shown, e.g., for different crystal forms of hexokinase which exhibit variable catalytic pro- perties; at least one of them is completely inactive (3).

Valid conclusions about the structural basis for activity should depend on structure and activity determinations employing the same material, if such data is intended to define a mechanism of action. However, while catalytic activity of enzymes is generally determined with enzyme solutions, total structure analysis cannot yet be performed in that physical state. Hence, for such comparisons, determination of the activity of enzyme crystals is the only feasible alternative approach which might at least indicate whether or not changes in activity accompany crystallization. Such kinetic studies on carboxypeptidase A $(47,59,60)$, carboxypeptidase B (1) and glycogen phosphorylase (27) show that the predominant effect of crystallization is a large decrease in $\mathbf{k}_{\text {cat }}$. In contrast, the activity of pig-heart lactate dehydrogenase is not affected by changes in physical state (7), and similar observations have been reported for other systems $(55,56)$. Hence, reductions in $\mathbf{k}_{\text {cat }}$ need not accompany enzyme crystallization, and it is clear that generalizations about the effects of crystallization on enzyme function have not yet emerged. Nevertheless, it is apparent that mechanistic interpretations of crystal structures must be based on a detailed examination of the activity associated with the structure in the particular crystal form examined. Fortunately, kinetic analysis of catalysis by crystals is readily feasible; it can therefore provide a valuable guide to the choice of crystals suitable for X-ray structure analysis, a seeming prerequisite for the design of mechanisms based on enzyme structure.

Bovine pancreatic carboxypeptidase $A$, the second zinc enzyme to be discovered (67) is now one of the best studied of all enzymes. Having virtually become the classic example of a metalloenzyme, its properties illustrate the significance of one out of a total of 4790 atoms to the ultimate function of the molecule and, further, the potential of a metal atom for the correlation of such function with the structure and conformation of the active center. 
B. L. VALLEE: Zinc and other active site metals as probes

\section{CARBOXYPEPTIDASE A General properties}

Mammalian and fish pancreas contain two zinc carboxypeptidases which catalyse the hydrolysis of amino acid residues from the carboxyl terminus of peptides and proteins; one, named $" A \ll$, prefers aromatic residues and the other, called $» B \ll$, is specific for basic residues (40). Both are synthesized in the pancreas as zymogens and their activation involves limited tryptic proteolysis. Carboxypeptidases A and B are now found as distinct and separate enzymes, but they may have evolved from a dually specific carboxypeptidase. Such an enzyme, the carboxypeptidase of Streptomyces griseus has, indeed, been found (12). Moreover, the properties of this bacterial enzyme, together with its close mechanistic similarity to carboxypeptidase A suggest that it may be the postulated intermediate between endopeptidases and the carboxypeptidases (42).

The most thoroughly characterized carboxypeptidase $A$ is that isolated from bovine pancreas. Its precursor, procarboxypeptidase $\mathrm{A}$, is a trimeric protein with a molecular weight of 89,000 (41). One of the subunits has a molecular weight of 41,000 and is the direct precursor of carboxypeptidase A. The other two subunits are identical and on treatment with trypsin give rise to chymotrypsin-like endopeptidase activity (acetyltyrosine ethyl esterase). Both the proteolytic action of trypsin and the activation of acetyltyrosine ethyl esterase then generate carboxypeptidase A, which has a molecular weight of 34,600 .

Three different forms of the bovine enzyme have been identified, $A_{\alpha}, A_{\beta}$, and $A_{\gamma}$, consisting of 307,305 and 300 amino acid residues respectively (43). The additional residues occur at the amino terminal region of the molecule.

Neurath and his collaborators have determined the amino acid sequence of carboxypeptidase $A_{\alpha}$ (11). It consists of 307 residues with a molecular weight of 35,268 .

$\mathrm{X}$-ray diffraction crystal analysis has confirmed the amino acid sequence studies, identified the $\alpha$-carbon and side chain positions in carboxypeptidase $\mathrm{A}$, and allowed the identification of the active-site residues (38). Thus, residue 145 , postulated to be the site of interaction of the free $\alpha$-carboxyl group of the substrate with the enzyme, is an arginyl residue, and the identity of
Table II

Activities of metallocarboxypeptidases.

\begin{tabular}{lcc}
\hline & \multicolumn{2}{c}{$\%$ Activity $\left(\mathrm{v} / \mathbf{v}_{\text {zinc }} \times 100\right)$} \\
\cline { 2 - 3 } Metal & Peptidase $^{\mathrm{a}}$ & Esterase $^{\mathrm{b}}$ \\
\hline Apo & 0 & 0 \\
Zinc & 100 & 100 \\
Cobalt & 200 & 114 \\
Nickel & 47 & 43 \\
Manganese & 27 & 156 \\
Cadmium & 0 & 143 \\
Mercury & 0 & 86 \\
Rhodium & 0 & 71 \\
Lead & 0 & 57 \\
Copper & 0 & 0 \\
\hline
\end{tabular}

a $0.02 \mathrm{M}$-benzyloxycarbonylglycyl-L-phenylalanine, $\mathrm{pH} 7.5,0^{\circ} \mathrm{C}$.

b 0.01 м-benzoylglycyl-DL-phenyllactate, $\mathrm{pH} 7.5$, $25^{\circ} \mathrm{C}$.

glutamate 270 , postulated to be the principal nucleophilic moiety, was confirmed. Other active-site residues include Tyr 198 and Tyr 248. The binding site of the zinc ion is composed of glutamate 72 and histidyl residues 69 and 196 . A water molecule completes a distorted tetrahedral geometry around the metal ion. Residues 138 and 161 , identified by X-ray analysis as half-cysteinyl residues, are joined by a disulfide linkage.

A zinc atom is essential to the catalytic activity of native carboxypeptidase A. As isolated the enzyme contains $1 \mathrm{gm}$-atom of zinc per molecular weight of 34,600 (67). Its removal totally inactivates the enzyme, whereas its readdition, or that of a number of other divalent metal ions, restores the dual activities of carboxypeptidase towards peptides and esters (Table II).

\section{Inorganic modifications as probes of enzymatic activity}

The broad substrate specificity of the enzyme is very responsive to the particular metal ion which is substituted for zinc. Thus, the cobaltsubstituted enzyme is twice as active as the native zinc enzyme toward peptides but its activity toward esters is nearly the same. The esterase and peptidase activities of the Ni(II)- and $\mathrm{Mn}(\mathrm{II})$-substituted enzymes are also diagnostic, 
while the $\mathrm{Cd}(\mathrm{II}), \mathrm{Hg}(\mathrm{II}), \mathrm{Rh}(\mathrm{II})$, and $\mathrm{Pb}(\mathrm{II})$ enzymes are significantly active only against esters. The copper enzyme, the alkaline-metal derivatives, and the enzymes substituted with most of the remaining transition metal ions are completely inactive towards both peptides and esters (Coleman and ValleE, 1960). Electron density difference maps show that in all the catalytically active metalloderivatives, except $\mathrm{Hg}$ (II) carboxypeptidase $\mathrm{A}$, the metal ion occupies the same site as the $\mathrm{Zn}$ (II) (21).

The spectroscopic properties of the substituent metal ions, particularly those of $\mathrm{Co}$ (II), have been used extensively as probes for the active site of carboxypeptidase $\mathrm{A}$ in the investigation of the interaction of the enzyme with substrates and inhibitors $(2,14,22,66)$.

As indicated above, the presence of a chromophoric metal atom at the active site of a met- alloenzyme such as carboxypeptidase provides an approach, unique to these systems, for the detection and study of local conformational changes on interaction with substrates and in the course of catalysis. The properties of the probe signals information about the state of the active center under different conditions of activity (66).

\section{Cobalt carboxypeptidase}

Cobalt carboxypeptidase $\mathrm{A}$ is active both as a peptidase and an esterase. Its visible absorption spectrum at room temperature (Figure 1) has a shoulder near $500 \mathrm{~nm}$ and maxima at 555 and $572 \mathrm{~nm}$, both with molar absorptivities of about 150 , and its infrared spectrum has bands at 940 and $1510 \mathrm{nM}(\varepsilon \sim 20)$. Lowering the temperature to $4{ }^{\circ} \mathrm{K}$ increases resolution of the visible bands but does not reduce absorptivity. Overall, the

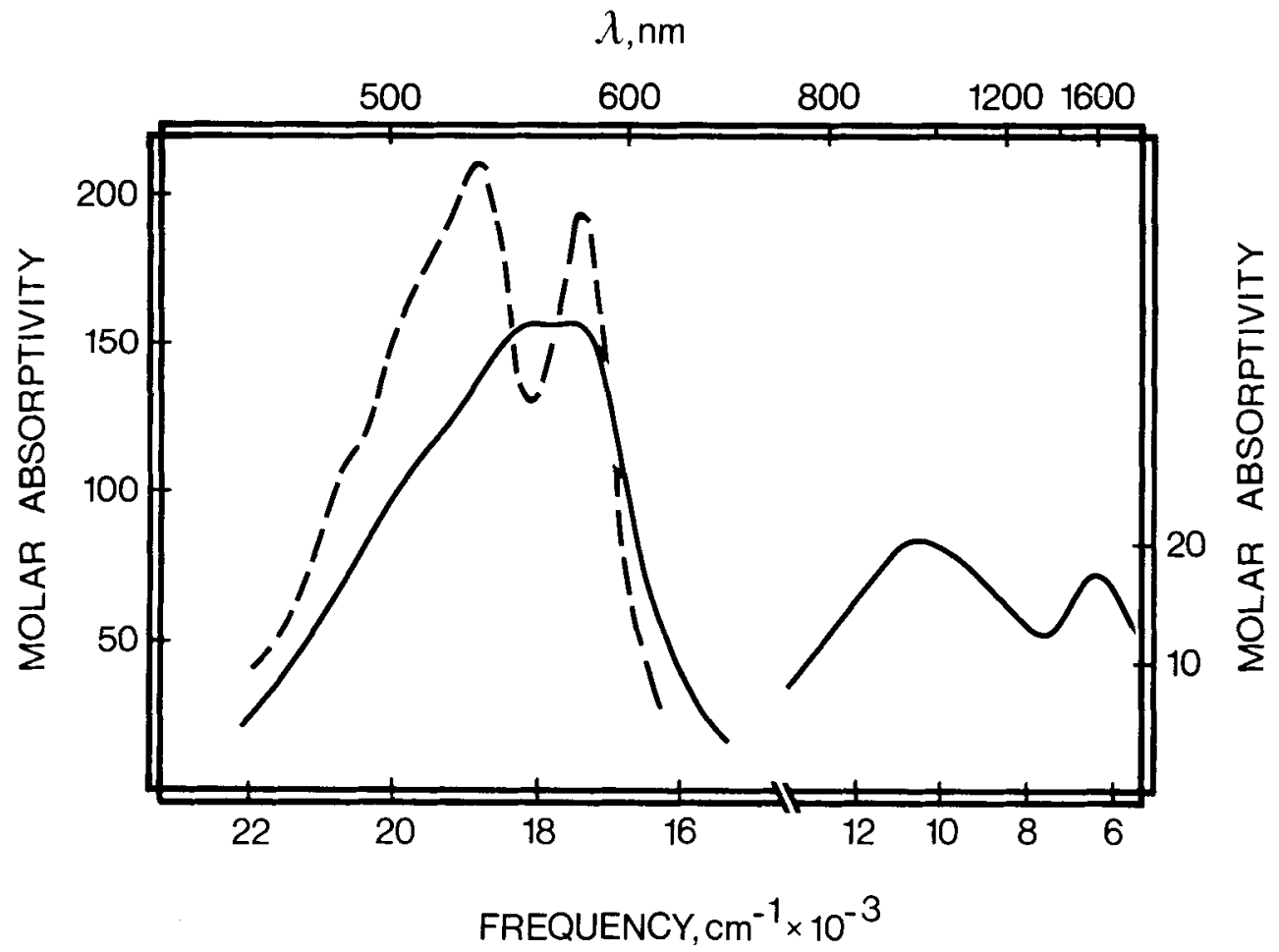

Figure 1. Absorption spectra of cobalt carboxypeptidase.

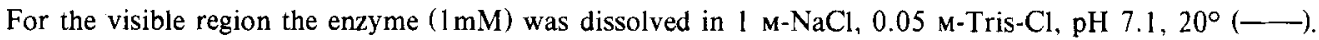
Another enzyme solution $(-3 \mathrm{~mm})$ was diluted with glycerol to $45 \% \mathrm{v} / \mathrm{v}$ and cooled to $4.2^{\circ} \mathrm{K}(\cdots)$ for spectral measurements.

For the near infrared region apocarboxypeptidase $(1.5 \mathrm{~mm}$ ) was dissolved in $1 \mathrm{M}-\mathrm{NaCl}, 0.005 \mathrm{M}-[\mathrm{D}] \mathrm{Tris}-\mathrm{Cl}$ in $\mathrm{D}_{2} \mathrm{O}, \mathrm{pD}$ 7.2. The sample cuvette contained $1.5 \mathrm{~mm}$ enzyme plus $\mathrm{CoSO}_{4}$ in $\mathrm{D}_{2} \mathrm{O}$ buffer to yield a final cobalt concentration of $2 \mathrm{~mm}$, and hence a $0.5 \mathrm{~mm}$ excess of free Co(II) ions. 
spectrum is indicative of irregular coordination geometry and tight bonding $(32,66)$, and may reflect an entatic metal environment (68). Since denaturing agents abolish the spectrum, its detection depends entirely on the existence of the three-dimensional structure of the protein.

The circular dichroic spectrum of the cobalt enzyme has a negative ellipticity band at $538 \mathrm{~nm}$ and a shoulder at about $500 \mathrm{~nm}$. A magnetic field only renders the absorption band at $572 \mathrm{~nm}$ optically active. Many inhibitors and pseudosubstrates perturb the circular dichroic spectrum suggesting concomitant rearrangements of the electron distribution about the cobalt atom in accord with a direct role of the metal in peptide hydrolysis. The metal thought to destabilize the peptide bond that is to be cleaved by coordinating with its carbonyl oxygen atom $(38,70)$.

The inner-sphere nature of the enzymesubstrate complex has been recognized by oxidation studies in which the substitution-labile $\mathrm{Co}$ (II) is converted in situ to the substitutioninert Co(III) atom. Co(III) carboxypeptidase A is entirely inactive toward both peptide and ester substrates (72).

\section{EPR studies of [(CPD) $\mathrm{Co}(\mathrm{II})] \cdot$ substrate and inhibitor complexes}

The complexes of cobalt(II)-substituted carboxypeptidase $\mathrm{A}_{\alpha}$, [(CPD)Co(II)], with inhibitors and the slowly hydrolyzed substrate glycyl-Ltyrosine have been characterized by electron paramagnetic resonance spectroscopy (epr). In all cases, the spectra are consistent with a high-spin $\mathrm{Co}$ (II) existing in a distorted tetrahedral coordination sphere. The spectrum of the free enzyme is independent of changes in $\mathrm{pH}$ over the range 5.5 to 10.0 , of changes in $\mathrm{NaX}$ concentration $(\mathrm{X}=\mathrm{F}, \mathrm{Cl}, \mathrm{Br}, \mathrm{I})$, or of crystallization; however, crosslinking the crystals with glutaraldehyde changes the spectrum significantly. Based on spectral features, complexes of the enzyme with inhibitors in solution can be divided into groups. Inhibitors with structurally identical features result in epr spectra which are similar in terms of $g$ values and spectral lineshape. Importantly, the slowly hydrolyzed substrate glycyl-Ltyrosine, which has both a metal coordinating group and substrate-like moieties, gives rise to an epr spectrum characteristic of the inhibitors which similarly have metal coordinating and specificity determining groups.

The structural characteristics of cobalt(II)substituted carboxypeptidase $\mathrm{A}_{\alpha}$ complexes with peptide and ester substrates formed at subzero temperatures have also been examined by electron paramagnetic resonance spectroscopy. Water-in-oil emulsions with an aqueous phase containing $2.5 \mathrm{M}-\mathrm{CaCl}_{2}$ provide an active, solution-like enzyme phase that can be cooled to approximately $-98^{\circ} \mathrm{C}$ without freezing of the water droplets. On mixing of enzyme and substrate emulsions in the temperature range from $-91^{\circ} \mathrm{C}$ to $-77^{\circ} \mathrm{C}$ an $\mathrm{E} \cdot \mathrm{S}$ complex forms. Warming to progressively higher temperatures changes the spectral features first to those of a second enzyme complex and ultimately to turnover of substrate (THOMPSON and VALLEE, unpublished results).

\section{Perturbed angular correlation of $\gamma$-rays (PAC)}

The substitution of cadmium for zinc results in an enzyme that is primarily an esterase and provides another means by which to probe the coordination geometry of the active site and its conformation: perturbed angular correlation of gamma rays (PAC). This method simultaneously detects changes in coordination geometry, in the charge of groups within $5 \AA$ of the metal nucleus, and delineates multiple states of the active center. Carboxypeptidase A crystals exhibit one predominant state while several are present in solution. Interpretation of the experimental data in terms of Angular Overlap Theory suggests the species characteristic of the crystals has a distorted tetrahedral coordination geometry and is in equilibrium with a pentacoordinated species in solution (6).

\section{Substitution of $\mathrm{Co}(\mathrm{II})$ in procarboxypeptidase as a gauge of the functional capacity of a zymogen}

Generally, it has been considered that zymogens are the inactive percursors of enzymes, their activation generating the catalytic and/or substrate binding properties of the enzyme (41). BeHNke and VALLEE (9) found that the spectral properties of $\mathrm{Co}(\mathrm{II})$-substituted procarboxypeptidase $\mathrm{A}$ and of $\mathrm{Co}$ (II) carboxypeptidase are virtually identical; both are peculiar to those of 
enzymatically active proteins (68). Remarkably, with certain substrates $\mathrm{Co}(\mathrm{II})$ procarboxypeptidase was found to be as active, and in some cases even more active, than the native enzyme. Subsequently, the kinetic characteristics of the native zinc zymogen were examined in detail (8). These, as well as earlier observations $(30,43$, 45 ), have raised questions regarding the concept that zymogens are necessarily inactive enzyme percursors.

\section{Syncatalytic measurement of distances}

Transfer of electronic excitation energy by fluorescence can be detected rapidly enough to allow examination of events that are synchronous with catalysis. The fluorescence of the dansyl group (5- $\mathrm{N}$-dimethylaminonaphthyl-1sulfonyl), which can serve as an N-terminal blocking group for peptide or ester substrates of carboxypeptidase (or other endo- or exopeptidases), overlaps cobalt absorption. Such $\mathrm{N}$-dansylated oligopeptides and ester substrates can therefore be used to measure distances between the cobalt atom and the substrate dansyl group within the enzyme active center, while simultaneously signalling other aspects of active center topography as the enzymatic reaction is in progress (33). The relay system involves enzyme tryptophanyl residues, the dansyl group of bound - but not of free - substrate, and the cobalt atom. The overlap of the fluorescence emission and absorption spectra are shown in Figure 2. The dansyl group plays a dual role in this system: it accepts energy transferred from tryptophan which it then transfers to the cobalt atom. Dissociation of the product after cleavage of the susceptible peptide bond disrupts the energy relay system $(33,34)$. The degree of quenching of the dansyl emission spectrum is a sensitive function of the distance between the dansyl group and the cobalt atom. When the dansyl group is relatively close to the cobalt atom, as for the dipeptide Dns-Gly-Phe, the emission of the dansyl group is quenched almost totally. But with longer peptides, e.g., Dns-Gly 2Phe or Dns-Gly ${ }_{3}$-Phe, the dansyl group is progressively farther away from the cobalt atom. The degree of dansyl quenching depends on the inverse sixth power of the distance between

\section{ENERGY DONOR-ACCEPTOR PAIRS}

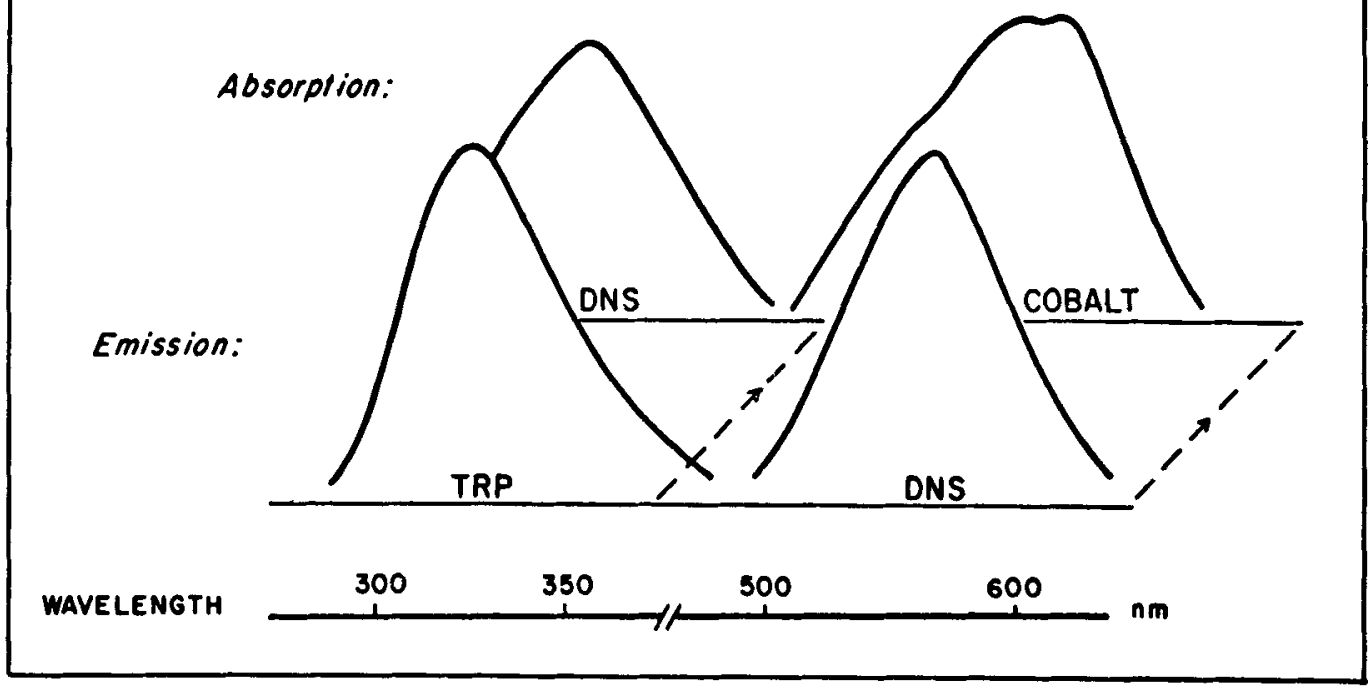

Figure 2. Schematic representation of the overlap relationships between enzyme tryptophan, substrate dansyl, and cobalt absorption and emission bands that constitute the energy donor-acceptor relay system critical to observation of the E-S complexes. 
Table III

Dansyl-cobalt distances in carboxy peptidase-substrate complexes ${ }^{\mathrm{a}}$.

\begin{tabular}{lcc}
\hline Substrate & $\mathrm{R} / \mathrm{nm}^{\mathrm{b}}$ & $\mathrm{R} / \mathrm{nm}^{\mathrm{b}}$ from CPK models \\
\hline Dns-Gly-L-Phe & $<0.8$ & 0.7 \\
Dns-Gly-L-Trp & $<0.8$ & 1.0 \\
Dns-Gly-Gly-L-Phe & $1.01-1.13$ & \\
Dns-Gly-Gly-L-Trp & $1.08-1.23$ & 1.3 \\
Dns-Gly-Gly-Gly-L-Phe & $1.17-1.27$ & 1.6 \\
Dns-Gly-Gly-Gly-L-Trp & $1.29-1.44$ & $1.41-1.47$ \\
Dns-Gly-Gly-Gly-Gly-L-Phe & 1.47 \\
\hline
\end{tabular}

a $1 \mathrm{~m}-\mathrm{NaCl}-0.02 \mathrm{M}-\mathrm{Tris}, \mathrm{pH} 7.5,25^{\circ} \mathrm{C}(34)$.

${ }^{b}$ The range of experimental values for the distance, $R$, reflects that of possible bound-substrate quantum yields.

${ }^{c}$ Measured on Corey-Pauling-Koltun molecular models from the centre of the dansyl group to the cobalt atom, assuming the peptide to be in an extended conformation and the metal to bind the oxygen atom of the $\mathrm{COOH}$ terminal peptide bond.

them, in accord with Forster's formulation of resonance energy transfer $(16,17)$.

The distances between the cobalt atom, acting at the susceptible peptide bond, and the dansyl group of bound substrates of varying length, determined experimentally by means of energy transfer $(33,34)$, are within the limits of those measured on CPK models of such peptides, assumed to be in an extended conformation (Table III). Further, the increases in distance as a function of peptide chain length are consistent for both the Phe and Trp sets of substrates, and for the corresponding members of the two sets as well.

The dansyl-cobalt energy transfer measurements determine the radii of arcs about the cobalt atom on which the dansyl group might lie. The intersection of these arcs with the enzyme surface define the regions surveyed by the dansyl peptide substrates, but substrate orientation within such contours remains to be determined.

\section{Enzymatic modification as a probe of the active center}

The principal functional constituents of carboxypeptidase encompass residues number 69 , 72 , and 196 as zinc binding ligands, 145 as a specificity site, and 248 and 270 as catalytic sites, thus extending over two thirds of the linear sequence of the protein molecule (38). As a consequence of three dimensional folding all of these residues are brought together and appropriately juxtaposed to generate the active site of the enzyme. A certain amount of structural stability is imposed on this organization by the presence of a disulfide bond linking residues 138 and 161 (11), but by and large the integrity of the active site is maintained solely by the polypeptide backbone and non-covalent side chain interactions. It is not surprising therefore that carboxypeptidase is quite susceptible to thermal denaturation. On the other hand, the native enzyme exhibits remarkable stability toward proteolytic inactivation. In particular, it can withstand exposure to fairly high concentrations of trypsin, chymotrypsin and elastase, an important property in its isolation from pancreatic juice.

One protease that has been found to be especially effective in digesting carboxypeptidase, however, is subtilisin, the seryl enzyme from Bacillus subtilis (type Carlsberg) which will rapidly and extensively degrade carboxypeptidase to low molecular weight oligopeptides (RIORDAN, in preparation). The details of this proteolysis process are most intriguing since it follows the classical »zipper mechanism« of TiseLIus (62) and LINDERSTRøM-LANG (36), in which a single bond is cleaved in all of the carboxypeptidase molecules prior to complete degradation. Importantly, by judicious choice of, among others, temperature and subtilisin concentration, it has proved possible to limit proteolysis, and hence isolate a unique intermediate, an enzymatically 
active species called carboxypeptidase-S. The most significant feature of this new form of the enzyme is its functional resemblance to derivatives of carboxypeptidase in which Tyr-248 has been modified chemically (see below). Thus, carboxypeptidase-S is similar to $\mathrm{O}$-acetylcarboxypeptidase in that it exhibits about five times the esterase activity but less than half the peptidase activity, of the native enzyme. These changes in activity appear to be brought about by the specific cleavage of a single peptide bond, as judged by $\mathrm{pH}$-titration and $\mathrm{N}$-terminal analysis. Initially, it was puzzling to find that the molecular weight of carboxypeptidase-S is the same as that of the native enzyme, even when measured in the presence of $8 \mathrm{M}$-urea. However, SDS-acrylamide gel electrophoresis in the presence and absence of 2-mercaptoethanol revealed that proteolysis takes place within the disulfide loop (between residues 138 and 161). Sequence studies (35) have identified the site of cleavage as the bond between Ser-157 and Ser-158, almost exactly in the middle of the molecule. A second cleavage occurs between Ala-154 and Gly-155, and this event is followed ultimately by extensive degradation. Insight into the structural consequences of the limited proteolysis of carboxypeptidase has been gained by using arsanilazocarboxypeptidase (52) (see below). Changes in the circular dichroic spectrum of the arsanilazotyrosyl residue indicate that cleavage of the 157-158 peptide bond perturbs the environment of Tyr-248. It has been postulated (35) that disruption of a multiple system of hydrogen bonds and charge interactions between Arg-145, Gly-155, Ala-154 and Gin-249, ultimately affects Tyr-248, so accounting for the changes in activity (RIORDAN, in preparation).

\section{Organic modifications as probes of the active center}

Chemical modification of active site residues is another means for studying local conformational changes. Through the use of a number of site-specific reagents, at least three, and perhaps four, different amino acid residues that are involved in the catalytic function of carboxypeptidase A have been identified (Table IV). Acetylation, iodination, nitration, and azocoupling with concomitant loss of peptidase activity $(26,53)$ have all singled out at least one essential tyrosyl residue, which quantitative sequence analyses have identified as tyrosine-248. Similarly, the modification of a single arginyl residue specifically alters peptidase activity (50). However, the modification of one carboxyl group with a carbodiimide reagent abolishes both activities (51). This carboxyl group is thought to be Glu-270. Both the complete amino acid sequence of carboxypeptidase (11) and X-ray structure analysis (46) are in accord with such chemical findings, and indicate that a carboxyl, an arginyl, and a tyrosyl residue are all suitably located in the active site to interact with substrate and, in conjunction with the zinc ion, to catalyze its hydrolysis.

\section{Table IV}

Changes in peptidase and esterase activities on modification of functional residues in carboxypeptidase $A$.

\begin{tabular}{lccc}
\hline & \multicolumn{2}{c}{ Control Activity (\%) } & Functional \\
\cline { 2 - 4 } Reagent & Peptidase $^{\mathrm{a}}$ & Esterase $^{\mathrm{b}}$ & $\begin{array}{c}\text { residue } \\
\text { modified }\end{array}$ \\
\hline Acetylimidazole & $<2$ & 700 & $\mathrm{Tyr}$ \\
Acetic anhydride & $<2$ & 610 & $\mathrm{Tyr}$ \\
Iodine & $<2$ & 500 & $\mathrm{Tyr}$ \\
Tetranitromethane & 14 & 190 & $\mathrm{Tyr}$ \\
5-Diazo-1H-tetrazole $(8 \times)$ & 90 & 180 & $\mathrm{Tyr}$ \\
5-Diazo-IH-tetrazole $(45 \times)$ & 5 & 180 & His \\
2, 3-Butanedione & 39 & 98 & Arg \\
Cyclohexyl-3-(2-morpholinoethyl) carbodiimide & 12 & 9 & Carboxyl \\
\hline
\end{tabular}

a $0.02 \mathrm{~m}$-benzyloxycarbonylglycyl-L-phenylalanine, $\mathrm{pH} 7.5,0^{\circ} \mathrm{C}$.

b $0.01 \mathrm{M}$-benzoylglycyl-DL-phenyllactate, $\mathrm{pH} 7.5,25^{\circ} \mathrm{C}$. 
The X-ray diffraction analysis has been extended to a study of the interaction of carboxypeptidase A with the pseudosubstrate glycyl-L-tyrosine. This study has served as the basis for the description of substrate-induced structural changes which, in turn, led to mechanistic inferences $(38,39)$. The X-ray data for the enzyme alone show that the phenolic hydroxyl group of tyrosine- 248 is located some $17 \AA$ away from the active site zinc atom, whereas the difference map of the Gly-L-Tyrcarboxypeptidase complex, in which only $\sim 1 / 3$ of the enzyme molecules interact with this pseudosubstrate (39), suggest that the phenolic group of this tyrosine swings around such as to approach the -NH- group of the potentially hydrolyzable peptide bond (46), a conformational change involving a movement of $12 \AA$. This motion has been cited (38) as the example par excellence of the induced fit theory of catalysis (31). The mechanism proposed for the catalysis of peptides based on the enzyme-Gly-L-Tyr complex incorporates a series of concerted structural changes presumed to occur on binding of substrate and ultimate hydrolysis of its susceptible peptide bond (38). Analogous data for carboxypeptidase-ester complexes do not exist and hence mechanistic conclusions for ester catalysis lack a structural basis. Recent data obtained on an enzyme complex with the ketonic agent 2-benzyl-3-p-methoxybenzoylpropionic acid (BMBP) in which the amide NH is replaced by $\mathrm{CH}_{2}$ (49) fail to resolve this dilemma.

Moreover, the examination of the absorption and circular dichroic spectra of a derivative of carboxypeptidase A in which tyrosine-248 is selectively labelled with diazotized arsanilic acid, a conformational probe $(23,24)$ have raised serious questions regarding the basic assumption underlying the hypothesis that the conformations of tyrosine-248 in solution and in the crystalline states are the same. Such studies of arsanilazocarboxypeptidase suggest that the physical state of an enzyme is an important variable and that the conformation of this enzyme in the crystals and solutions studied is quite different.
PHYSICAL STATE/CONFORMATION DEPENDENCE OF CARBOXYPEPTIDASE A.

a) Monoarsanilazo Tyr-248 carboxypeptidase

Zinc arsanilazocarboxypeptidase, the product of coupling crystalline carboxypeptidase with diazotized arsanilic acid, contains one arsanilazotyrosyl-248 residue per molecule, with no other residues being modified. It is almost fully active toward peptide and ester substrates (26). In the crystalline state this derivative is yellow but turns red when dissolved, as manifested by the corresponding absorption spectra (Figure 3). Removal of the active site zinc atom from the enzyme in solution abolishes the red color; the absorption band at $510 \mathrm{~nm}$ then disappears and the resultant spectrum is virtually identical with that of the crystalline zinc enzyme. The spectral characteristics of all three forms of arsanilazocarboxypeptidases $A_{\alpha}, A_{\beta}$, and $A_{\gamma}$ are the same.

The circular dichroic spectrum of the zinc azoenzyme in solution contains one positive and two negative ellipticity bands at 420,335 , and $510 \mathrm{~nm}$, respectively (Figure 4). Removal of zinc abolishes virtually the entire visible circular dichroic spectrum and the addition of $1 \mathrm{gm}$ atom of zinc per mole of enzyme completely restores it. This effect of zinc on both the absorption and circular dichroic spectra suggests that the red color of the enzyme in solution is due to the formation of a zinc-azophenol coordination complex. Indeed, closely similar color changes are observed on addition of zinc to a typical azophenol compound, tetra-azolyl-N-benzyloxycarbonyl-tyrosine. The spectrum of the free azophenol resembles that of crystalline azocarboxypeptidase and that of the metal complex is like that of the azoenzyme in solution.

Spectral pH-titrations of zinc azocarboxypeptidase in solution between $\mathrm{pH} 6.2$ and $\mathrm{pH} 8.3$ generate the absorption band at $510 \mathrm{~nm}$, typical of the azophenol-zinc complex. Above $\mathrm{pH} 8.3$ this band shifts progressively to $485 \mathrm{~nm}$, characteristic of the free azophenolate ion. In contrast, the metal-free azoenzyme only forms the band at $485 \mathrm{~nm}$. These differences become more apparent on plotting absorbance versus $\mathrm{pH}$ for the zinc and zinc-free azoenzymes. The titration of the zinc azoenzyme at $560 \mathrm{~nm}$ reveals two $\mathrm{pK}_{\text {app }}$ values at 7.7 and 9.5 respectively, whereas the titration of the apoenzyme at 458 $\mathrm{nm}$ results in a sigmoid curve with a midpoint at 


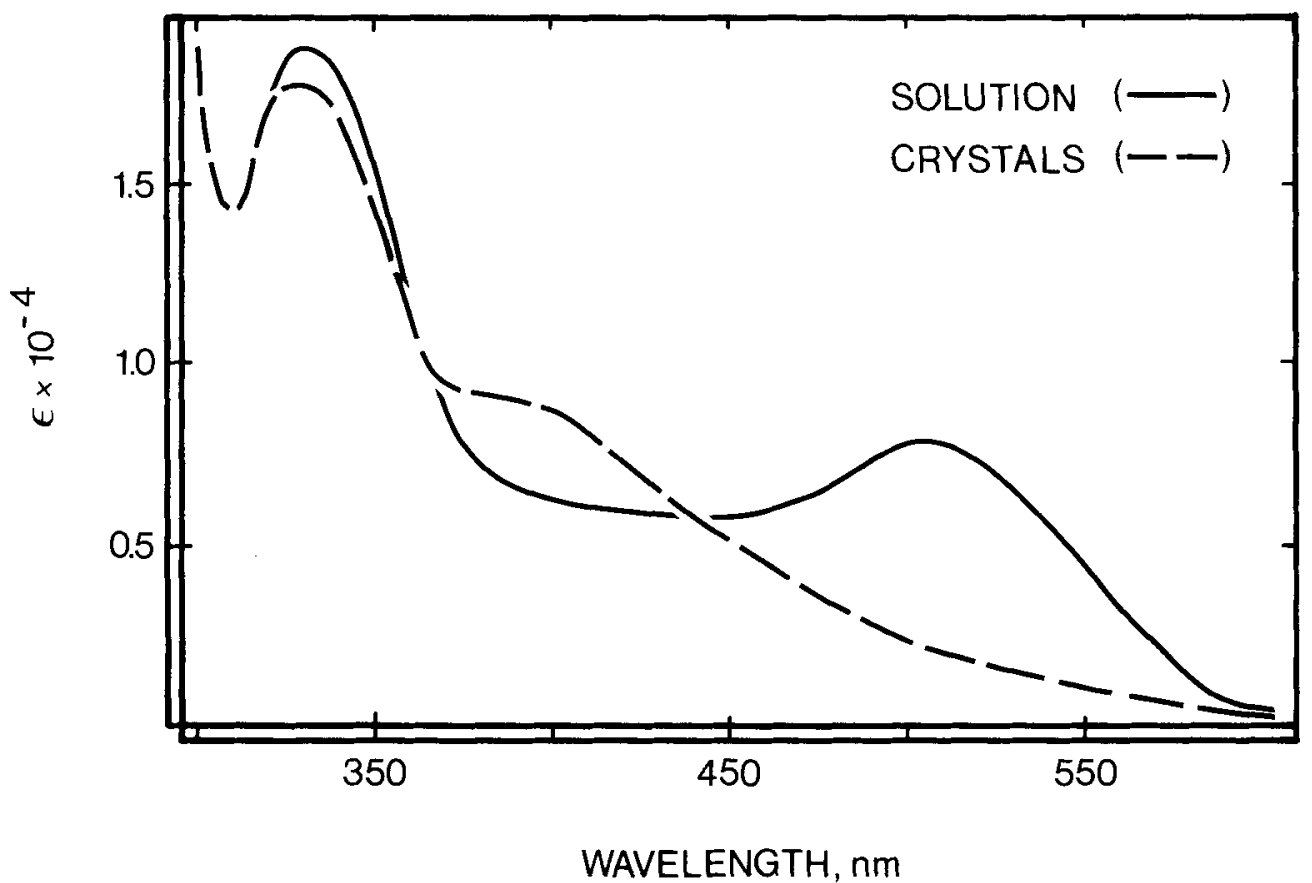

Figure 3. Absorption spectra of zinc arsanilazocarboxypeptidase (--) dissolved in $0.05 \mathrm{~m}-\mathrm{Tris}-\mathrm{HCl} / 1 \mathrm{M}-\mathrm{NaCl}(\mathrm{pH}$ 8.2), and of zinc arsanilazocarboxypeptidase crystals suspended in $0.05 \mathrm{M}-\mathrm{Tris}-\mathrm{HCl}(\mathrm{pH} 8.2)(\ldots)$.

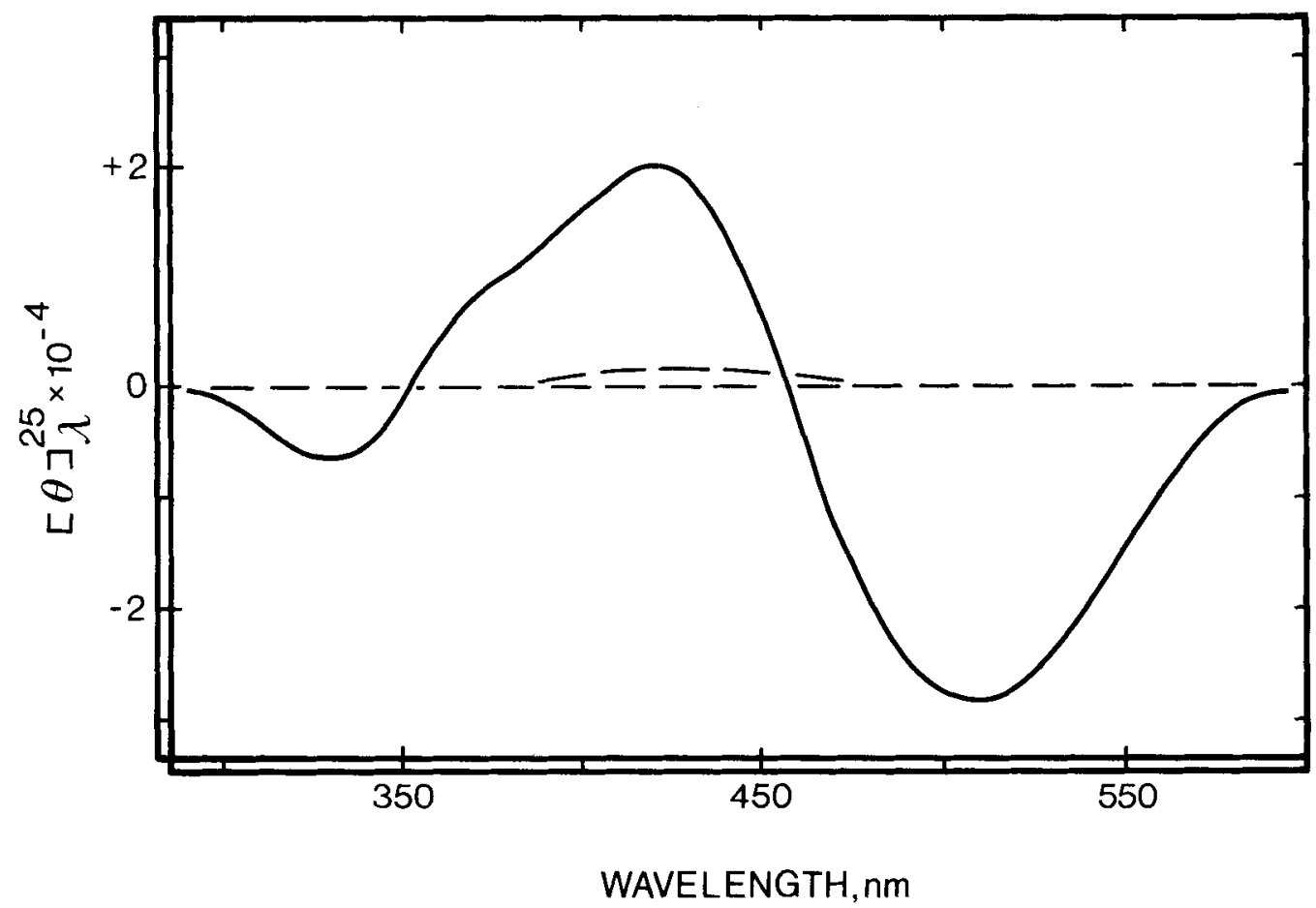

Figure 4. Circular dichroism of zinc arsanilazocarboxypeptidase (--) and of the corresponding apoenzyme (--) dissolved in $0.05 \mathrm{M}-\mathrm{Tris}-\mathrm{HCl} / 1 \mathrm{M}-\mathrm{NaCl}(\mathrm{pH} 8.2)$. 
$\mathrm{pH}$ 9.4, characteristic of the ionization of arsanilazophenol. Similarly, when followed by circular dichroism at $510 \mathrm{~nm}$, the $\mathrm{pH}$-titration curves for the zinc enzyme reveal the same two $\mathrm{pK}_{\mathrm{app}}$ values, 7.7 and 9.5, where the titration of the apoenzyme monitored at $485 \mathrm{~nm}$ again has a single $\mathrm{pK}_{\mathrm{app}}$ of about 9.4 .

Based on a series of studies with model azophenol-metal complexes, such data indicate that in solution the enzyme forms an intramolecular coordination complex between arsanilazotyrosine-248 and the active site zinc ion $(23,24$, 25).

\section{b) Resonance Raman (rR) spectroscopic studies of arsanilazo Tyr-248 carboxypeptidase. Structure of the intramolecular coordination complex}

Resonance Raman (rR) studies have now confirmed all the above conclusions, including the apparent $\mathrm{pK}$ values for the interconversions of the various species $(57,58)$. Moreover, based on the study of model compounds and on isotope substitutions, the $r R$ bands corresponding to the motions of the specific atoms involved in the formation of the intramolecular coordination complex have been assigned $(57,58)$, and its structure has been deduced, thereby obviating any questions regarding its existence (Figure 5). The $\mathrm{rR}$ studies demonstrate further that the $\mathrm{OH}$ group of tyrosine-248 in the azocrystals is probably hydrogen-bonded to another residue of the enzyme, which thus prevents the coordination of Tyr-248 to the zinc ion in the crystals (58). The complex observed in solution obviously could not form if tyrosine- 248 were $17 \AA$ away, as it is in the native crystals. These data therefore render questionable the mechanistic deductions based on the crystal structure analysis (38).

\section{c) NitroTyr-248 carboxypeptidase}

It is unlikely that the probe itself induces changes in the protein conformation (48), and studies with nitrocarboxypeptidase, a chemical derivative with completely different characteristics (53) confirm the principles of these findings. Thus the reaction of tetranitromethane with carboxypeptidase crystals specifically nitrates tyrosine-248. In solution nitrocarboxypeptidase

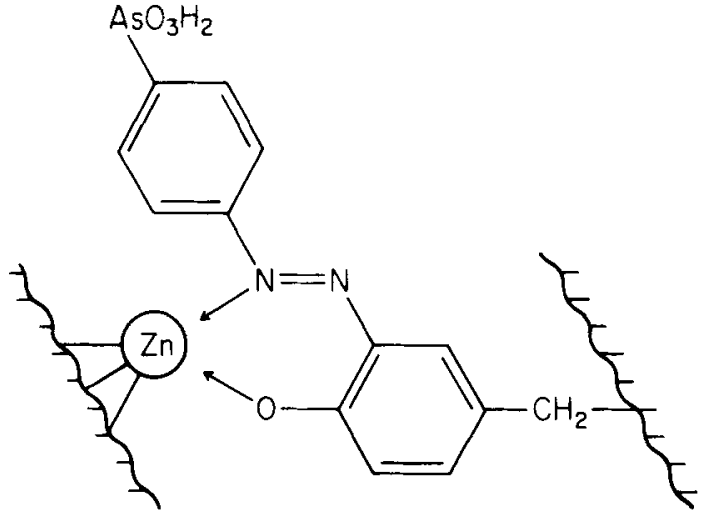

Figure 5. Structure of the azotyrosine-248-zinc complex of arsanilazotyrosine-248 carboxypeptidase $A$, as deduced from its $r R$ spectra.

exhibits a visible absorption band with a maximum at $428 \mathrm{~nm}$, which titrates with a $\mathrm{pK}$ of about 6.3. Relative to model nitrophenols this pK is abnormally low. This has been attributed to the proximity of a positive charge from the protein to the nitrotyrosyl residue. Studies with a series of nitrotyrosyl-containing copolymers support this hypothesis. The midpoint of the titration curve of a copolymer of glutamic acid and nitrotyrosine is at $\mathrm{pH} \mathrm{7.1.} \mathrm{As} \mathrm{the} \mathrm{charge} \mathrm{of}$ the copolymer becomes more positive, nitrotyrosyl ionization shifts progressively to lower $\mathrm{pH}$ values such that the $\mathrm{pKa}$ of nitrotyrosyl in polylysylnitrotyrosine is 6.1 .

The studies of Johansen and Vallee $(23,24$, 25 ) suggest that the positive charge influencing the ionization behavior of nitrotyrosine- 248 in nitrocarboxypeptidase is the active-site zinc ion. Titration of nitrocarboxypeptidase crystals results in a midpoint at $\mathrm{pH} 8.3$, compared with $\mathrm{pH}$ 6.4 for the enzyme in solution. This dramatic shift in titration behavior, solely due to a change in the physical state of the enzyme, indicates that both in nitrocarboxypeptidase and in arsanilazocarboxypeptidase the conformation of tyrosine-248 differs in solution from that in the crystalline state.

Such data indicate the need for a re-evaluation of past views on the structural features of carboxypeptidase catalysis and, further, raise questions on whether analogous conformational differences between solutions and crystals may escape detection for want of suitable methods. It 
is apparent that spectrochemical probes of the type described here offer distinct opportunities in this regard.

\section{DETECTION OF MULTIPLE BINDING MODES AT THE ACTIVE SITE OF CAR- BOXYPEPTIDASE A BY CIRCULAR DI- CHROISM - INHIBITOR TITRATIONS}

Specific introduction of the azo group into Tyr- 248 results in two discrete probes, which signal distinctively different perturbations by virtue of their optical activity, on one hand, of the active center azoTyr-248 itself, and, on the other, of the azoTyr-248-Zn chelate. Each can detect the same and/or different interactions and environmental changes. This greatly magnifies the potential as probes of these optically active chromophores, thereby revealing important aspects of the topography of the active center and its interaction with inhibitors and substrates in solution.

Titration of the azoenzyme with a series of synthetic, competitive inhibitors, e.g., L-benzylsuccinate, L-Phe, and L-phenyllactate and the pseudosubstrate, Gly-L-Tyr, in turn generates characteristic circular dichroic spectra $(2,25)$. Their analysis reveals a single binding constant for each of these agents, one molecule of each binding to the active center. Different spectral effects characterize the competitive and noncompetitive components of mixed inhibitions. Two molecules of mixed inhibitors bind to the enzyme, consistent with both thermodynamic and enzymatic studies. The interactions leading to competitive and noncompetitive inhibition, respectively, can be recognized and assigned, based on the manner in which the extrema at 340 and $420 \mathrm{~nm}$, reflecting azoTyr-248, and the negative $510 \mathrm{~nm}$ circular dichroism band, typical of its chelate with zinc, are affected and on the $\mathrm{pH}$ dependence of spectral and kinetic data.

In solution azoTyr-248 forms a chelate with $\mathrm{Zn}$ at $\mathrm{pH} 8.5$, and all agents here studied disrupt it, as demonstrated by studies of metal-substituted enzymes, competition between different inhibitors and substrates, and magnetic circular dichroism titrations of the cobalt enzyme.

Further stopped-flow and temperature-jump studies demonstrate a completely analogous set of events at the very moment of catalysis. Close proximity between Tyr-248 and the zinc atom must be an essential feature of the enzyme's mechanism of action.

\section{INTRAMOLECULAR ARSANILAZOTYRO- SINE-248 - Zn COMPLEX OF CARBOXY- PEPTIDASE A \\ (1) A monitor of catalytic events}

To detect local changes in conformation, essential to and synchronous with catalysis, such specific spectral probes must also have suitably fast response times. The electronic, magnetic, and structural changes accompanying some of the site-specific inorganic and organic enzyme modifications discussed are sensors of conformational changes accompanying catalysis. Further, the spectra of the chromophoric intramolecular coordination complex between arsanilazotyrosine- 248 and the zinc atom of azocarboxypeptidase respond dynamically to environmental factors, e.g., $\mathrm{pH}$, substrates, inhibitors, and denaturing agents, as well as the physical state of the enzyme.

The dynamics of the interconversion of the azoTyr-248- $\mathrm{Zn}$ complex and its constituents have been measured by stopped-flow $\mathrm{pH}$ and temperature-jump methods (20). The rate of interconversion, $64,000 \mathrm{sec}^{-1}$, is orders of magnitude faster than that of the catalytic step itself (about 0.01-100 $\mathrm{sec}^{-1}$ ). Peptide and ester substrates which are turned over rapidly disrupt the azoTyr-248. $\mathrm{Zn}$ complex before hydrolysis occurs. As a consequence, substrate binding and catalysis can be monitored while catalysis is actually in progress. Rapid changes in $\mathrm{pH}$ result in spectral changes analogous to those induced by substrates which, therefore, are not unique to them. If azoTyr-248 is displaced, the direction is opposite to the inward movement postulated on the basis of X-ray studies (38).

AzoTyr-248 carboxypeptidase has all features which are necessary for mechanistic studies: this derivative is enzymatically active; the spectra of its metal complex differ characteristically from those of its constituents; the derivative responds dynamically to environmental factors; and the response time of its probe is much more rapid than is required for the measurement of the catalytic step, thus allowing the discernment of microscopic details of the catalytic process. 


\section{(2) A monitor of multiple conformational states in solution}

The azoprobe reveals the existence of rapidly interconvertible substructures of carboxypeptidase $\mathrm{A}$, and the results support the view that, in solution, enzymes can adopt multiple, readily interconvertible and related conformations which could then either facilitate or impede catalysis. In crystals, rearrangement of molecular structure could be severely impaired or restricted, and crystallization might single out either active or inactive conformations. In the latter case, such crystals would have greatly reduced activities and markedly altered catalytic behavior, as is observed for carboxypeptidase A. In combination with detailed kinetic analysis of crystals, conformational analysis in solution should be a valuable guide to discern enzyme mechanisms and select crystals functionally and structurally suitable for $\mathrm{x}$-ray structure analysis.

\section{PHYSICAL STATE DEPENDENCE OF CATALYTIC ACTIVITY: CRYSTALS AND SOLUTIONS}

Kinetic analyses of the crystalline enzyme have provided a different approach to this problem, and should prove valuable in overcoming problems generated by different enzyme conformations caused by different physical states. While it has not proven possible as yet to perform threedimensional structure analysis in solution, it has proven possible to perform detailed kinetic analysis of substrate hydrolysis catalyzed by crystals $(59,60)$. Thus detailed kinetic studies of carboxypeptidase A crystals and solutions show that the physical state of the enzyme is a critical parameter that affects this enzyme's function. A series of peptides and esters varying in blocking groups and chain length were examined. In all instances crystallization of the enzyme markedly reduces catalytic efficiency, $k_{\text {cat }}$, from 20-1000fold. In addition, substrate inhibition, apparent in solution for some di- and depsipeptides, is abolished in the crystals, and longer substrates which exhibit normal kinetics in solution may exhibit activation when hydrolyzed by crystals. The physical state of the enzyme also affects the mode of action of known modifiers of peptidase activity of the enzyme. In solution, addition of benzoylglycine or cinnamic acid, for example, markedly increases the rate of hydrolysis of Cbz-Gly-Phe but, with the crystalline enzyme, their addition hardly alters the activity. This is in accord with the weakening or absence of inhibitory enzyme-substrate binding modes.

The results of kinetic studies with crystals carried out over a wide range of crystal sizes and of enzyme and substrate concentrations in all instances are in good agreement with Katchalski's (28) theory for enzymes insolubilized by other means. Importantly, these kinetic parameters were determined under conditions which obviate artifacts due to diffusion limitation of substrates or products. The differences in the kinetic behavior of carboxypeptidase crystals on the one hand, and of their solutions on the other, bear importantly on efforts to interpret the function of the enzyme in structural terms. Hypothetical modes of substrate-enzyme interaction deduced from model-building by superimposition of the substrate on the crystal structure of carboxypeptidase, so purporting to simulate the kinetics of the enzyme in solution, have failed to detect all of the changes which affect inhibitory or activating binding modes. In conclusion, while it is not yet possible to examine the tertiary structure of enzymes in solution, it is possible to study the enzymatic activity of the crystals. In effect such data constitute a functional probe of the conformation dominant in the crystals compared to that found in solution. The study of different crystals should prove a valuable guide to the choice of those suitable for structure analysis and such evaluations would seem indispensible for the design of mechanisms based on enzyme structure and function.

\section{STRUCTURE AND FUNCTION OF CAR- BOXYPEPTIDASE $A_{a}$ IN SUPERCOOLED WATER}

The ultimate verification of reaction mechanisms of enzymes demands the determination of their functional and structural characteristics with the same substrates under identical experimental conditions. However, ideal circumstances for the performance of standard kinetic and thermodynamic experiments vary widely. Whereas rapid kinetics call for excellent substrates, thermodynamic techniques often utilize inhibi- 
tors or pseudosubstrates. Hence, the two approaches can result in quite divergent views of the formation, characteristics, and breakdown of a given enzyme-substrate complex. At present, the structural basis of enzymatic activity is generally deduced from time-averaged procedures at thermodynamic equilibrium, whereas functional conclusions often rest on pre-steady-state or steady-state conditions at »kinetic equilibrium《. Owing to the vastly different time frames in which structure and function of enzymes can be assessed at conventional temperatures, it has proven most difficult to delineate the structure of the enzyme-substrate complex at the moment of catalysis.

Reduction of temperature to subzero levels is an obvious potential means of reducing or eliminating this disparity. The establishment of conditions, media, and instrumentation for the study of enzymes in aqueous-organic cryosolvents has led to the detection of transient species in enzyme reactions. Our studies of a water-inoil emulsion (a reversed micellar system) provides a medium with a temperature range from at least $+38^{\circ} \mathrm{C}$ to $-38^{\circ} \mathrm{C}$ by supercooling water without freezing and without requiring changes in composition of that medium.

Carboxypeptidase $\mathrm{A}$ is active over the entire range of temperatures in which the aqueous phase remains liquid $\left(+25^{\circ} \mathrm{C}\right.$ to $\left.-38^{\circ} \mathrm{C}\right)$. In solution at $25^{\circ} \mathrm{C}$ and in emulsions at temperatures as low as $-38^{\circ} \mathrm{C}$, the absorption spectra of chromophoric derivatives of the enzyme are virtually identical. The data demonstrate that supercooled water-in-oil emulsions are suitable for studies of both function and structure under identical reaction conditions (61). The integration of approaches that allow direct visualization of ES complexes through the placement of probes within the enzyme and/or substrates with those that permit low temperature rapidmixing and observation conditions should allow detection of conformational changes which may accompany binding of substrate to an enzyme, as well as the subsequent catalytic and product release steps. We expect that the combination of experiments such as described above performed both under equilibrium and kinetic conditions at low temperatures will allow mechanistic conclusions more realistic than those feasible for either time frame alone.

\section{SPECIFICITY OF CARBOXYPEPTIDASE A TOWARD PEPTIDES AND ESTERS - MECHANISTIC IMPIICATIONS}

Another difficulty that has faced the X-ray crystallographic approach in deciphering enzyme mechanisms is the inability to examine enzymesubstrate complexes (see above). To circumvent this problem enzyme complexes with inhibitors, products or pseudosubstrates have been employed. Thus, as discussed above, mechanistic deductions for carboxypeptidase A have been based on results obtained using the complex of the enzyme with the pseudosubstrate glycyl-Ltyrosine $(38,39)$. This dipeptide is known to form both a "productives and a "non-productive complex, the former turning over quite slowly, the latter not at all. Most likely it was the unproductive complex which was examined crystallographically. An analogous enzyme ester substrate complex which is suitable for X-ray crystallographic analysis has not been reported; the ketonic substrate BMBP (49) does not qualify. It is known that carboxypeptidase behaves quite differently toward ester and peptide substrates (see above). Thus, the kinetic parameters for peptide hydrolysis of a series of metal substituted carboxypeptidases show that the $\mathrm{k}_{\text {cat }}$ values range from $6000 \mathrm{~min}^{-1}$ for the cobalt enzyme down to $43 \mathrm{~min}^{-1}$ for the cadmium enzyme (4). The $K_{m}$ values, on the other hand, depend almost totally on the particular metal present. For ester hydrolysis the exact opposite is true. $K_{\mathrm{m}}$ varies from $3300 \mathrm{M}^{-1}$ for the cobalt enzyme to $120 \mathrm{M}^{-1}$ for the cadmium enzyme, whereas $\mathrm{k}_{\text {cat }}$ is essentially unchanged.

Such effects of a given metal ion on the binding of ester - but not of peptide - substrates can be visualized directly. By using stopped-flow procedures and flourescence energy transfer, AuLD and HoLmQuist (4) have demonstrated unequivocally that peptides such as dansyl-(glycyl) ${ }_{3}$ phenylalanine bind to the metal-free enzyme but are not hydrolyzed. In contrast their exact ester analogs, e.g., dansyl-(glycyl) ${ }_{3}$ phenyllactate, do not bind to the apoenzyme. A number of other mechanistic differences between ester and peptide substrates of carboxypeptidase A have also been observed (Table V).

The cumulative evidence leads to the conclusion that the enzyme employs different catalytic 
B. L. VAlLEE: Zinc and other active site metals as probes

Table V

Metallocarboxypeptidase-catalyzed hydrolysis of $\mathrm{Bz}-(\mathrm{Gly})_{2}-\mathrm{L}-\mathrm{Phe}$ and $\mathrm{Bz}-(\mathrm{Gly})_{2}-\mathrm{L}-\mathrm{OPhe} \mathrm{a}^{\mathrm{a}}$.

\begin{tabular}{|c|c|c|c|c|}
\hline & \multicolumn{2}{|c|}{ Bz-(Gly) 2-L-Phe } & \multicolumn{2}{|c|}{$\mathrm{Bz}-(\mathrm{Gly})_{2}$-L-OPhe } \\
\hline & $\underset{\left(\mathrm{min}^{-1}\right)}{\mathrm{k}_{\mathrm{cat}}}$ & $\begin{array}{c}10^{-3} \mathrm{~K}_{M^{-1}} \\
\left(M^{-1}\right)\end{array}$ & $\begin{array}{l}10^{-4} k_{\text {cat }} \\
\left(\min ^{-1}\right)\end{array}$ & $\begin{array}{l}\mathrm{K}_{\mathrm{M}}^{-1} \\
\left(\mathrm{M}^{-1}\right)\end{array}$ \\
\hline Cobalt & 6000 & 1.5 & 3.9 & 3300 \\
\hline Zinc & 1200 & 1.0 & 3.0 & 3000 \\
\hline Manganese & 230 & 2.8 & 3.6 & 660 \\
\hline Cadmium & 41 & 1.3 & 3.4 & 120 \\
\hline
\end{tabular}

${ }^{a}$ Assays performed at $25^{\circ} \mathrm{C}, \mathrm{pH}=7.5,1.0 \mathrm{M}-\mathrm{NaCl}$, and a buffer concentration of $0.05 \mathrm{~m}$-Tris for peptide hydrolysis and $10^{-4} \mathrm{M}$-Tris for ester hydrolysis (4).

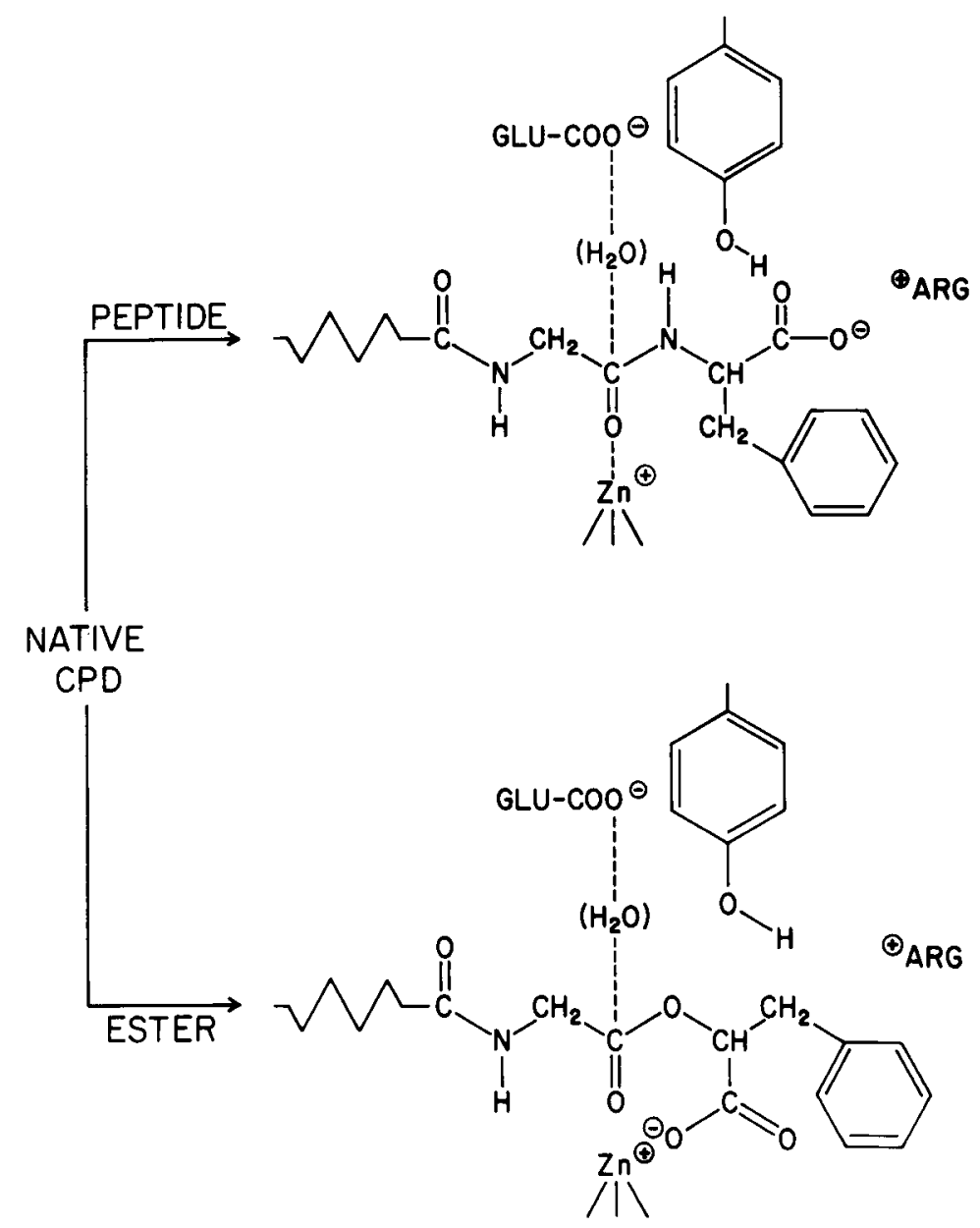

Figure 6. Mechanistic schemes for the (a) peptidase and (b) esterase activities of carboxypeptidase A. 
mechanisms for these two classes of substrates (71). A possible means to account for this difference is illustrated in Figure 6. The upper panel indicates that the hydrolysis of peptides involves the participation of the carboxyl group of glutamic acid-270, probably acting as a general base on the substrate carbonyl group, which is activated by the metal atom at the active-site. Tyrosine- 248 is thought to facilitate the breakdown of a resulting tetrahedral intermediate. Specificity resides in the orientation of the terminal carboxyl group through interaction with an arginyl residue of the enzyme.

At the bottom panel, esters, lacking the potential of forming the hydrogen bond with tyrosine-248, are thought to bind differently. Kinetic evidence (4) indicates that the esters bind through the metal atom, and chemical modification studies (50) rule out the arginyl residue as the site which is essential for ester binding. Consequently, the ester is depicted to bind to the metal atom through its carboxyl group, rather than to the guanido group of arginine. The role of tyrosine- 248 is thus less essential to ester than to peptide hydrolysis. It is apparent that a realistic discussion of the mechanism of carboxypeptidase A action must account for the hydrolysis of both peptide and ester substrates. It is likely that the extension of studies at low temperatures will resolve the remaining ambiguities to result in a more definitive view.

\section{REFERENCES}

1. Alter, G. M., D. L. Leussing, H. Neurath \& B. L. ValleE: Biochemistry 16, 3663 (1977)

2. Alter, G. M. \& B. L. Vallee: Biochemistry 17 , 2212 (1978)

3. Anderson, W. F., R. J. Fletterick \& T. A. Steitz: J. Mol. Biol. 86, 261 (1974)

4. Auld, D. S. \& B. Holmquist: Biochemistry 13, 4355 (1974)

5. Auld, D. S., H. Kawaguchi, D. M. Livingston \& B. L. VAlleE: Proc. Natl. Acad. Sci. USA 71, 2091 (1974)

6. Bauer, R., C. Christensen, J. T. Johansen, J. L. Bethune \& B. L. Vallee: Biochem. Biophys. Res. Commun. 90, 679 (1979)

7. Bayne, S. \& M. Ottesen: Carlsberg Res. Commun. 41, 211 (1976)

8. Bazzone, T. J.: Fed. Proc. 33, 1722 (abstr.) (1974)
9. Behnke, W. D. \& B. L. Vallee: Proc. Natl. Acad. Sci. USA 69, 2442 (1972)

10. Blake, C. C. F.: FEBS Lett. 62 (suppl), E30 (1976)

11. Bradshaw, R. A., L. H. Ericsson, K. A. Walsh \& H. Neurath: Proc. Natl. Acad. Sci. USA 63, 1389 (1969)

12. Breddam, K., T. J. Bazzone, B. Holmquist \& B. L. VAlleE: Biochemistry 18, 1563 (1979)

13. Carpenter, F. H. \& J. M. Vahl: J. Biol. Chem. 248, 294 (1973)

14. Coleman, J. E. \& B. L. Vallee: J. Biol. Chem. $235,390(1960)$

15. Drum, D. E., J. H. Harrison, T.-K. LI, J. L. Bethune \& B. L. Vallee: Proc. Natl. Acad. Sci. USA 57, 1434 (1967)

16. Forster, T.: Ann. Phys. 2, 55 (1948)

17. Forster, T.: In: Modern Quantum Chemistry, Part III, (O. Sinanoglu, ed.), p. 93, Academic Press, New York (1965)

18. Harris, M. I. \& J. E. Coleman: J. Biol. Chem. 243,5063 (1968)

19. Harrison, L. W., D. S. Auld \& B. L. Vallee: Proc. Natl. Acad. Sci. USA 72, 4356 (1975)

20. Harrison, L. W., D. S. Auld \& B. L. Vallee: Proc. Natl. Acad. Sci. USA 72, 3930 (1975)

21. Hartsuck, J. A. \& W. N. Lipscomb: In: The Enzyme, vol. III (3rd ed., P. D. Boyer ed.), p. 1, Academic Press, New York (1971)

22. Holmquist, B., T. A. Kaden \& B. L. Vallee: Biochemistry 14, 1454 (1975)

23. Johansen, J. T. \& B. L. Vallee: Proc. Natl. Acad. Sci. USA 68, 2532 (1971)

24. Johansen, J. T. \& B. L. Vallee: Proc. Natl. Acad. Sci. USA 70, 2006 (1973)

25. Johansen, J. T. \& B. L. ValleE: Biochemistry 14,649 (1975)

26. Johansen, J. T., D. M. Livingston \& B. L. VALLEE: Biochemistry 11, 2584 (1972)

27. Kasvinsky, P. J. \& N. B. Madsen: J. Biol. Chem. 251, 6852 (1976)

28. Katchalski, E., I. Silman \& R. Goldman: Advan. Enzymol. 34, 445 (1971)

29. Kellin, D. \& J. ManN: Biochem. J. 34, 1163 (1940)

30. KaY, J. \& B. Kassell: J. Biol. Chem. 246, 6661 (1971)

31. Koshland, D. E., Ir.: Proc. Natl. Acad. Sci. USA 44, 98 (1958)

32. Latt, S. A. \& B. L. Vallee: Biochemistry 10, $4263(1971)$

33. Latt, S. A., D. S. Auld \& B. L. Vallee: Proc. Natl. Acad. Sci. USA 67, 1383 (1970)

34. Latt, S. A., D. S. Auld \& B. L. Vallee: Biochemistry 11, 3015 (1972) 
35. Lee, H. M. \& J. F. Riordan: Fed. Proc. 35, 1963 (1976)

36. Linderstrøm-LaNG, K.: Lane Medical Lectures, Vol. VI, Stamford University Press (1952)

37. Linderstrøm-Lang, K. \& J. A. Schellman: In: The Enzymes (2nd ed., P. D. Boyer, ed.), vol. I, p. 443, Academic Press, New York (1959)

38. Lipscomb, W. N., J. A. Hartsuck, G. N. Reeke, Jr., F. A. Quiocho, P. H. Bethge, M. L. Ludwig, T. A. Steitz, H. Muirhead \& J. C. Coppola: Brookhaven Symp. Biol. 21, 24 (1968)

39. Lipscomb, W. N., G. N. Reeke, J. A. Hartsuck, F. A. Quiocho \& P. H. Bethge: Phil. Trans. Roy. Soc. London, B257, 177 (1970)

40. Neurath, H.: In: The enzymes (2nd ed., P. D. Boyer, ed.), vol 4A, p. 11, Academic Press, New York (1960)

41. Neurath, H.: Fed. Proc. 23, 1 (1964)

42. Neurath, H. \& R. Bradshaw: Acc. Chem. Res. 3, 249 (1970)

43. Neurath, H., R. A. Bradshaw, P. H. Petra \& K. A. Walsh: Phil. Trans. Roy. Soc. London, Ser. B 257, 159 (1970)

44. Parisi, A. F. \& B. L. ValleE: Amer. J. Nutr. 22, $1222(1969)$

45. Piras, P. \& B. L. Vallee: Biochemistry 6, 348 (1967)

46. Quiocho, F. A. \& W. N. LipscomB: Advan. Protein Chem. 25, 1 (1971)

47. Qurocho, F. A. \& F. M. Richards: Biochemistry 5, 4062 (1966)

48. Quiocho, F. A., C. H. McMurray \& W. N. LipscomB: Proc. Natl. Acad. Sci. USA 69, 2850 (1972)

49. Rees, D. L., R. B. Hozatko \& W. N. Lipscomb: Proc. Natl. Acad. Sci. USA 77, 3288 (1980)

50. Riordan, J. F.: Biochemistry 12, 3915 (1973)

51. Riordan, J. F: \& H. Hayashida: Biochem. Biophys. Res. Commun. 41, 122 (1970)

52. Riordan, J. F. \& D. M. Livingston: Biochem. Biophys. Res. Commun. 44, 695 (1971)

53. Riordan, J. F. \& G. Muszynska: Biochem. Biophys. Res. Commun. 57, 447 (1974)
54. Rosenbusch, J. P. \& K. Weber: Proc. Natl. Acad. Sci. USA 68, 1019 (1971)

55. Rossi, G. L. \& S. A. Bernhard: J. Mol. Biol. 49, $85(1970)$

56. SAWYer, L.: J. Mol. Biol. 71, 503 (1972)

57. Scheule, R. K., H. E. Van Wart, B. L. Vallee \& H. A. Scheraga: Proc. Natl. Acad. Sci. USA 74, 3273 (1977)

58. Scheule, R. K., H. E. Van Wart, B. L. Vallee \& H. A. Scheraga: Biochemistry 19, 759 (1980)

59. Spilburg, C. A., J. L. Bethune \& B. L. Vallee: Proc. Natl. Acad. Sci. USA 71, 3922 (1974)

60. Spilburg, C. A., J. L. Bethune \& B. L. Vallee: Biochemistry 16, 1142 (1977)

61. Thompson, J. S., H. Gehring \& B. L. Vallee: Proc. Natl. Acad. Sci. USA 77, 132 (1980)

62. Tiselius, A. \& I.-B. Eriksson-Quensel: Biochem. J. 33, 1752 (1939)

63. Vallee, B. L.: Advan. Protein Chem. 10, 317 (1955)

64. Vallee, B. L.: Physiol. Rev. 39, 443 (1959)

65. ValleE, B. L.: In: New trends in bio-inorganic chemistry (R. J. P. Williams \& J. R. R. F. daSilva, eds.), p. 11, Academic Press, London (1979)

66. Vallee, B. L. \& B. HolmquisT: In: Methods for determining metal ion environments in proteins, Las Cruces, New Mexico (1980)

67. Vallee, B. L. \& H. Neurath: J. Amer. Chem Soc. 76, $5006(1954)$

68. Vallee, B. L. \& R. J. P. Williams: Proc. Natl Acad. Sci. USA 59, 498 (1968)

69. Vallee, B. J., E. A. Stein, W. N. Sumerwell \& E. H. FisCher: J. Biol. Chem. 234, 2901 (1959)

70. Vallee, B. L., J. F. Riordan \& J. E. Coleman: Proc. Natl. Acad. Sci. USA 49, 109 (1963)

71. Vallee, B. L., J. F. Riordan, J. L. Bethune, T. L. COOmbs, D. S. Auld \& M. SoKolovsky: Biochemistry 7, 3547 (1968)

72. Van Wart, H. E. \& B. L. Vallee: Biochem. Biophys. Res. Commun. 75, 732 (1977)

73. Weber, G.: Adv. Protein Chem. 29, 1 (1975) 